\title{
Interactional Justice and Employees' Commitment to Supervisor in Nigerian Health Sector
}

\author{
Ajogwu Akoh, Edwinah Amah
}

\author{
Department of Management, University of Port Harcourt, Rivers State, Nigeria
}

\begin{abstract}
This research was designed to study the relationship between interactional justice and employees' commitment to supervisor in Nigerian health sector. A self-administered survey questionnaire was sent out to a sample size of 103 employees, resulting in 99 responses out of which 13 copies of the questionnaire were not statistically usable. The Spearman rank correlation coefficient was used for data analysis, and our findings reveal that employees who have received fair informational and interpersonal treatments commit themselves to their supervisors. We discovered that the degree of influence exerted by interpersonal justice on employees' commitment to supervisor was stronger than that of informational justice. We concluded that employees attach themselves to supervisors that are fair in communication and relationship. The fairness of interaction and communication boost employees' confidence, impacting positively on employees' commitment to supervisor and making employees see themselves as part owners in the organization. We, therefore, recommended that organizational managers or supervisors should communicate and relate properly with employees, in order to satisfy their customers and other stakeholders.
\end{abstract}

Keywords: Interactional justice, Informational justice, Interpersonal justice, Employees' commitment to Supervisor, Identification with supervisor, Internalization of supervisor's values

\section{Introduction}

A number of studies have concluded that the commitment of an employee to the supervisor is a positive outcome to pursue. These studies found different forms of interactions between employees' commitment to supervisors and a number of other variables (Becker, Billings, Eveleth and Gilbert, 1996; Chen, Tsui and Farh 2002; Gregerson, 1993). The work of Becker et al. (1996) discovered that employees' commitment to supervisor is positively associated with job performance and return a stronger association than the degree of association generated by overall organizational commitment and performance. Winston (2004) in Sokoll (2014, p.91) proposed that commitment to the supervisor is enhanced by servant leadership. A similar position was taken by Ebener and O'Connell (2010). In the work of Nwibere and Olu-Daniels (2014) trust was found to be of positive influence on employees' commitment to supervisors. Colquitt, Conlon, Wesson, Porter and $\mathrm{Ng}$ (2001) held that unjust treatments in organizations could lead to employees' withdrawal from the organization. Supervisors play an important role in managing this problem. The relationship between the employees and their supervisors tend to shape the duty or values the employee owes to or holds of the organization.

From the foregoing submissions, it can be deduced, that commitment to the supervisor can positively impact organizational prosperity if enhanced. Hence, the need for studies that promote employees' commitment to supervisor has become imperative. The diversity and sophistication of today's workforce place a demand on organizations for improved relationships and communications among internal customers in the workplace. Today's organizational effectiveness should be judged by the smoothness of the relationships, communications and interactions within and without the 


\section{Ajogwu Akoh, Edwinah Amah \\ Interactional Justice and Employees' Commitment to Supervisor in Nigerian Health Sector}

organizations. People and Knowledge have become critical in achieving organizational objectives and moving organizations to the next level. This demands organizational supervisors to manage people rightly. It is reasonable to firmly establish that efficient and effective organizations are those that are able to enhance employees' commitment to their supervisors. To achieve this positive end, therefore, we propose the use of interactional justice - maintaining the dignity of persons during interpersonal relationships and communicating respectfully when dealing organizational members or employees.

Some studies that examined supervisor's treatment of subordinates with interactional justice found that interactional justice leads to a better leader-subordinate relationship. The researchers observed that high quality leader-subordinate and leader-team members' relationships helped motivated employees to achieve better job performance (Cropanzano, Prehar and Chen, 2002). Suggestions from the work of Tsai $(2012$, p. 37) indicate that justice can inspire employees to go beyond the call of their formal duties and behave altruistically toward others. Hence, we believe that interactional justice can best reinforce such a commitment behavior of employees. Tsai suggested that employees' commitment to supervisor impacts positively on employees' organizational citizenship behaviors (OCBs), which in turn helps the organization to meet the needs or mandates of its clients or stakeholders.

The perceived justice of treatment of employees with respect, dignity and politeness is a wearisome subject in Nigerian organizations. Many Nigerian organizations are guilty of what McManus (2002) described as management by nagging (a lot) - "the prolific use of e-mails, bulletin board postings, mailbox contributions and meeting agenda items that are intended to make people change." This position, no doubt makes employees and managers to merely coexist as loosely couple assets, capable of dissipating at any time. The effective implementation of interactional justice - the fairness of communications and interpersonal relationships in organizations will improve employees' commitment, not only to their jobs but also to their supervisors and other foci of organizational commitments.

Studies have demonstrated how organizational justice impacts on organizational citizenship behaviour (Cohen-Charash and Spector, 2001); Trust and commitment (Colquitt, 2001); Job satisfaction (Bateman and Organ, 1983); and a myriad of other positive organizational outcomes. Haven established in our earlier submissions that distributive justice enhances employees' commitment to supervisor (Akoh and Amah, 2015), we now study interactional justice. In the present study, interactional justice was solely demonstrated and confirmed as capable of influencing employees' commitment to supervisor. This fills a gap in the literature, since no known study has investigated this relationship, especially in the Nigerian health sector. The conceptual framework for conducting this enquiry is shown hereunder.

The results of this study will have important usefulness for organizations in the Nigerian health sector. The impact of the relationship formed between a supervisor/manager, and the employees are proposed to impact positively on ultimate organizational profitability. Some limitations were encountered in the course of this study. The selected hospitals for investigation were not fully receptive to the study. In the bid to avoid the likelihood of becoming competitively vulnerable, hospitals were unwilling to surrender sensitive organizational information. Researchers' identities were subjected to serious scrutiny at the Rivers State Ministry of Health, where the selected hospitals information was originally sourced. There was a need for researchers to submit ethical approval and even demonstrate research procedure for scrutiny. All these processes were not free from organizational bureaucracy in the Nigerian public institutions. The study was only conducted in the Nigerian health sector, particularly in Rivers State and excluding the public hospitals, as well as primary and tertiary hospitals. Only employees who had supervisors were chosen as the unit of analysis. 


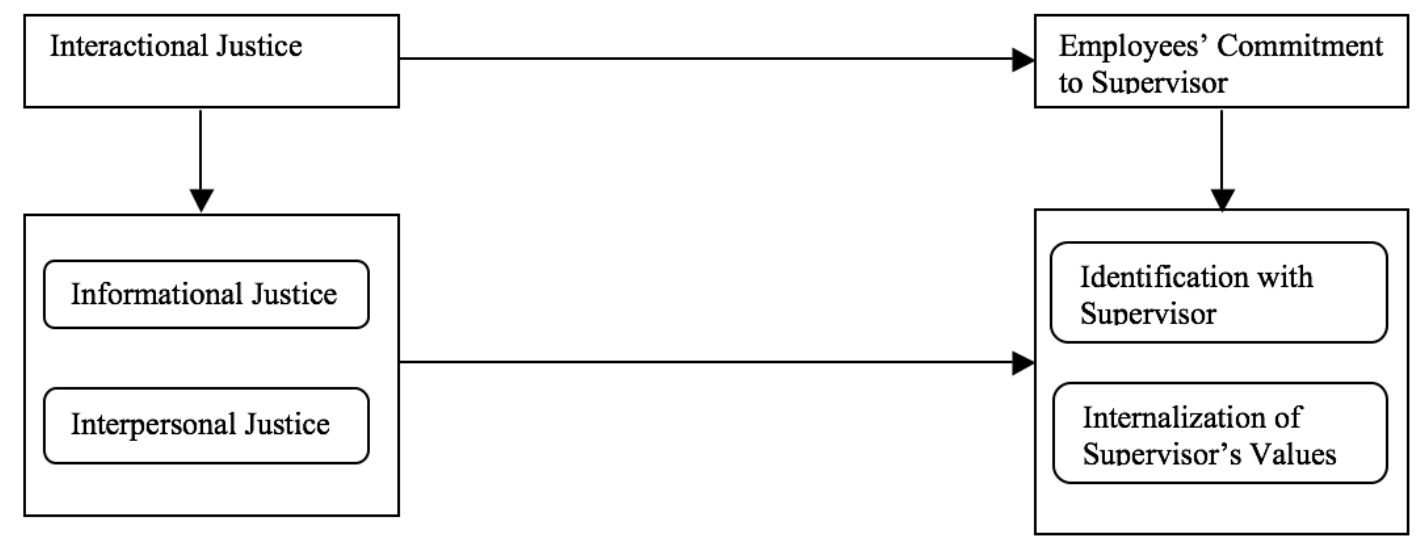

Figure 1: Conceptual Framework

Source: Conceptualized by the researchers.

Drawing from the research model above, this study's main purpose of verifying the impact of interactional justice on employees' commitment to supervisor was derived. Additionally, the study is set out to specifically investigate the following relationships:

i. The correlation between informational justice and identification with supervisor.

ii. The correlation between informational justice and internalization of supervisor's values.

iii. The correlation between interpersonal justice and identification with supervisor.

iv. The correlation between interpersonal justice and internalization of supervisor's values.

From the foregoing research purpose(s), the main focus research question was generated - What is the correlation between interactional justice and employees' commitment to supervisor? More specifically, this study will answer the questions provided hereunder:

i. What is the correlation between informational justice and identification with supervisor?

ii. What is the correlation between informational justice and internalization of supervisor's values?

iii. What is the correlation between interpersonal justice and identification with supervisor?

iv. What is the correlation between interpersonal justice and internalization of supervisor's values?

The following research hypotheses were, in turn, put forward for testing.

i. Informational justice is not significantly related to identification with supervisor.

ii. Informational justice is not significantly related to internalization of supervisor's values.

iii. Interpersonal justice is not significantly related to identification with supervisor.

iv. Interpersonal justice is not significantly related to internalization of supervisor's values.

\section{Review of related literature}

\subsection{Interactional justice}

According to Folger and Cropanzano, (1998), "Interactional justice relates to the quality of relationships between individuals within organizations." With reference to interactional fairness, it is important to consider the way people who make decisions treat those their decisions affect. This is because people see attitude and behavior as pointers to fairness in the organization. Masterson, Lewis, Goldman and Taylor (2000) defined interactional justice as what subordinates perceive and how those subordinates respond to their perceptions; relating to how their supervisors treat them. Aside to the justice of outcomes and procedures, researchers have also found that the quality of interpersonal treatment that an individual receives has a tremendous effect on his/her perception of justice. This subject matter was termed by Bies and Moag (1986) in Tsai (2012) as "interactional justice". Bies and Moag explained that the assessment of interactional justice focused on the interaction, which was not covered by formal procedures. Hence, it should be conceptually different from procedural justice and separated as a unique dimension of the organizational justice construct. 
According to Bies and Moag (1986) in Tsai (2012), there are four fundamental elements of interactional justice:

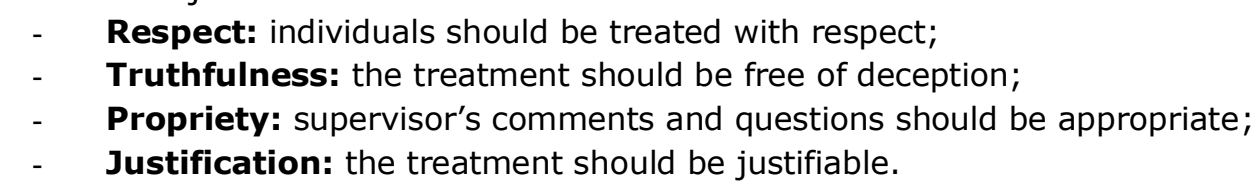

The researchers opined that interactional justice is concerned with the nature of treatments received by employees when supervisors/managers make decisions. To enhance these treatments, managers are expected to provide sufficient explanations regarding decisions made and communicate relevant information respectfully and sensitively. Colquitt (2001) probed the validity of interactional justice construct and offered that interactional justice ought to be subdivided to include: interpersonal and informational justice. The former deals with treatments perceived as respectful and appropriate, while the latter was seen as the fairness and adequacy of the explanations given by supervisors, which must be timely, specific and truthful. Supervisors and organizational authorities interact with employees when they implement procedures or communicate decisions or outcomes to employees. Interpersonal justice "reflects the degree to which people are treated with politeness, dignity, and respect by authorities who determine employees' outcomes or implement organizational procedures" (Tsai, 2012). The other justice type - informational justice "focuses on explanations provided to people that convey information about why given procedures were used in a certain way or why given outcomes were distributed in a certain fashion."

Tsai (2012, p. 35) suggested that the relative prominence of interactional justice, as it concerns the manner people are treated and the adequate provision of information; makes the employeesupervisor relationship appraisable. This is because; the two components of interactional justice often dominate daily transactions between employees and supervisors and directly influence employees' perceptions and response attitudes. Mikula, Petri and Tanzer (1990) stated that a good portion of unjust organizational practices was unrelated to distributive and procedural issues. Instead, the study suggested that certain types of perceived workplace injustice bordered on the manner of interpersonal treatments people receive during workplace interactions and encounters.

\subsection{Response to injustice}

Organizations that allow workplace injustices do not go unpunished! There are different ways individuals may respond to their feelings of unjust treatments in the workplace. These responses to injustice may vary from one organization to another. In most cases, depending on the weakness of the legal and/or regulatory framework or provisions in the external environment of the given organization, employees are unable to question unjust organizational policies. Even when employees unite to air their grievances, management may remain adamant and in extreme cases, punish selected individuals. Sheppard, Lewicki and Minton (1992) observed that, in such a situation, only an individual employee or group of employees are attacked or punished by the organizational authorities.

Research has shown that, when employees are treated unequally, they may choose to reduce or increase their inputs in order to align same with the outcomes they receive from the organization. With reference to interactional injustice, Lind and Tyler (1988) mentioned that it would be difficult to predict employees' responses. However, Bies and Shapiro (1987) found that interactional justice is good for predicting reactions toward supervisors or managers and the decisions they make. Turnley and Feldman (1999) offered four possible responses to unjust treatments of employees in the workplace. The researchers disclosed that dissatisfied employee may choose to leave the organization, reduce his efforts, show resentment or neglect the injustice. These are suggestions that show organizational managers that workplace injustices are unwelcome and where such injustices exist, the organization does not go unpunished, as many managers think. 


\section{Ajogwu Akoh, Edwinah Amah \\ Interactional Justice and Employees' Commitment to Supervisor in Nigerian Health Sector}

\subsection{Employees' commitment to supervisor}

Procedural justice has a longer usage than employees' commitment to supervisor. Chen, Tsui and Farh, (2002); Gregersen (1993) and Becker, Billings, Eveleth and Gilbert, (1996) in their studies, offered two items to measure employees' commitment to supervisor - identification with supervisor and internalization of supervisor's values. Gregersen (1993) confirmed the significant association of commitment to supervisor with extra role behavioral disposition of respondents whose stay in the organization was more than 2 (two) years (p. 42-43).

Becker et al. (1996) tried to know the nature of association between employees' commitment and performance, "as a multidimensional phenomenon" (p. 465). The study probed into the concept of varieties targets with reference to the commitment of employees in an organization. The study also investigated the motivations that inform such a commitment to the given targets. In line with the work of Kelman (1958), Becker et al. (1996) divided the bases into three types: compliance, identification, and internalization (Sokoll, 2014, p. 93). The study discovered that the commitment of employees to supervisor had a stronger link to performance compared to the commitment of the employees to the organization as a whole.

In another study, Chen et al. (2002) explored the importance of commitment to supervisor and the impact it had on work outcomes in the relationship-oriented Chinese culture. Because of the peculiarity of the Chinese society, which is characterized by close interpersonal relationships, commitment to another person like the supervisor could be more important and mean something different. Chen et al. (2002) concluded that "loyalty to supervisor seems to be more important than organizational commitment in predicting employee's in-role and extra-role performance" (p. 352). The researchers further proposed that the stronger impact that loyalty to supervisor has on employees' outcomes is a phenomenon that could cut across cultural boundaries. Hence they suggested that research should be conducted in different cultural contexts, both within and outside China.

\subsection{Identification with supervisor}

Identification occurs, according to Gregersen (1993) and Becker et al. (1996), when a subordinate looks up to certain attributes of his supervisor with admiration. This may come with the dignity of persons having relationships with such a supervisor, hence becoming committed to the given supervisor. "The subordinate, however, may or may not adopt the supervisor's attributes as his or her own" (O'Reilly and Chatman, 1986, p. 493 in Chen et al. 2002, p. 340). The subordinate shows a proud disposition for being associated with the given supervisor. It involves the subordinate's attribution of the supervisor's characteristics to himself or herself.

\subsection{Internalization of supervisor's values}

According to Becker et al. (1996); Gregersen (1993); Chen et al. (2002), employees internalize the supervisor's values when they learn and adopt the supervisor's way of life because the supervisor's way of life aligns with the subordinates' value. Internalization is the state of existence characterized with the subordinate interiorizing the values of the supervisor. This implies that the subordinate's values are similar to those of his/her supervisor. This, the researchers referred to as a state of congruity of values between the supervisor and the subordinate.

\subsection{The extended dimensions of commitment to supervisor}

Chen et al. (2002) postulated that employee-supervisor loyalty might go beyond identification and internalization in a highly relationship-oriented context because of social norms. Employees may become attached to a supervisor as a result of: "Closeness, ethnic affiliations, religious affiliations, the frequency of relationship, the need to reciprocate a given kind gesture or because of an obligation bound to be rendered to an authority figure" (Chen et al., 2002, p. 341). Based on the foregoing postulations and review of earlier studies, the researchers expanded the conceptualization of commitment to supervisor to include "the attachment and dedication of employees to the supervisor." 


\section{Ajogwu Akoh, Edwinah Amah \\ Interactional Justice and Employees' Commitment to Supervisor in Nigerian Health Sector}

Chen et al. (2002, p. 342). According to Chen et al. (2002, p.345-347), the foregoing proposition led them to develop the following items to measure the construct of commitment to supervisor.

a. Identification with supervisor: This occurs when the subordinate holds the supervisor's accomplishment in high esteem and has a proud disposition for being associated with or subordinated to the given supervisor.

b. Internalization of the supervisor's values: This is the state of existence characterized with the congruity of values between the subordinate and the supervisor. The subordinate sees the supervisor's value system as appropriate and shares similar philosophies of life with the given supervisor.

c. Dedication to supervisor: This involves the readiness of an employee to give and pledge allegiance to the supervisor; to primarily subordinate his personal interests to those of the supervisor.

d. Extra effort for supervisor: This deals with the readiness of the subordinate to exert more than the required energies to satisfy the interests of the supervisor.

e. Attachment to supervisor: This deals with the willingness of the employee to connect with the supervisor.

Nwibere and Olu-Daniels (2014) adopted the Chen, et al (2002) five dimensions in their own work. They labeled the first two dimensions as original dimensions and the last three as extended dimensions. The branding as extended dimensions was based on extractions from Chen et al. (2002) scale which is an extension of Becker et al's (1996) two-dimensional scale or measure of the construct. This position was originally taken by Chen et al (2002) and later mentioned in the work of Nwibere and Olu-Daniels (2014).

\section{METHODOLOGY}

A survey questionnaire was administered and used to collect data from target respondents. With the aid of observation, we studied the justice climate as demonstrated by side comments, observable work attitudes, mode of response to patients and other observed gesture statements of employees. Data were collected from six hospitals registered with the state ministry of health. All six hospitals were private hospitals, with a total population of 138 (one hundred and thirty-eight) employees. Using the Taro Yemeni procedure for determining sample size, 103 (one hundred and three) copies of the questionnaire were distributed to employees constituting a mix of nurses, doctors and administrative staffs, provided the individual has a supervisor. Copies of the questionnaire returned were 99 (ninety-nine). Of the copies returned, only 86 (eighty-six) were statistically usable.

\subsection{Validity and reliability}

The research instrument for this study was adapted from the work of experts. Procedural justice items were adapted from Colquit (2001) and commitment to supervisor items was based on the earlier work of Becker et al. (1996). The research instrument was subjected to validity test, by giving same to experts who verified the correctness and appropriateness of the questions adopted. The research instruments were originally tested for reliability, using Cronbach's alpha coefficient test. The items included in the scale were adapted after a critical review of related literature to interactional justice and commitment to supervisor. The Cronbach's alpha for the variables include: interactional justice (0.943); identification with supervisor (0.71) and internalization of supervisor's values $(0.70)$

\subsection{Measures}

This study used Colquitt's (2001) measures of interactional justice, which assessed the extent of fair interactions reflected in the experiences of correspondents; measured on a 7-point Likert scale ( $1=$ strongly disagree, $7=$ strongly agree). Four items measured interpersonal justice and investigated if the supervisors have treated the individuals politely, with dignity, with respect and refrained from improper comments. Informational justice was measured with five items, determining whether or not the supervisors have: (a) been candid in communication (b) explained decisional procedures thoroughly (c) given reasonable explanations for the procedures used (d) communicated details in a 
timely manner (e) tailored communications to individual's specific need. When tested for scale reliability by Colquitt (2001) in McCardle (2007), the interactional justice items returned an alpha value of 0.943 .

The measures of Commitment to Supervisor used for this work were adopted from Becker et al. (1996). These are Identification with supervisor and Internalization of supervisor's values. These sample items were referred to as the original dimensions of commitment to supervisor in the work of Chen et al. (2002). It was required of respondents to indicate the extent of their agreement or disagreement with the given items, using a Likert Scale of 1 to 7 . A score of 1 for strongly disagree, whereas 7 is strongly agree. Becker et al. (1996) observed 2 (two) measures of commitment to supervisor: Identification with supervisor incorporated the following 5 items: (i) I feel personally insulted when someone criticizes my supervisor (ii) When talking about my supervisor, I will say "we" not "they" (iii) When my supervisor is successful, I am also successful (iv) I take my supervisor's compliments as my personal compliments ( $v$ ) I feel a sense of mutual ownership between me and my supervisor. The internalization of supervisor's values included 4 items: (i) I would not have attached myself to my supervisor, if he/she had entirely different interests. (ii) I am attached to my supervisor, because of the similarity of our values (iii) My values began to align with that of my supervisor since I started this job (iv) I prefer my supervisor, because of his values.

\section{RESULTS AND INTERPRETATION}

\subsection{Informational justice and identification with supervisor (hypothesis one) \\ H1: Informational justice is not significantly related to Identification with Supervisor}

Table 1: Test of hypothesis one: Correlations

\begin{tabular}{|c|c|c|c|c|}
\hline & & & Informational & Identification \\
\hline \multirow[t]{6}{*}{ Spearman's rho } & \multirow[t]{3}{*}{ Informational } & $\begin{array}{l}\text { Correlation } \\
\text { Coefficient }\end{array}$ & 1.000 & $.572^{* *}$ \\
\hline & & Sig. (2-tailed) & & .000 \\
\hline & & $\mathrm{N}$ & 86 & 86 \\
\hline & \multirow[t]{3}{*}{ Identification } & $\begin{array}{l}\text { Correlation } \\
\text { Coefficient }\end{array}$ & $.572^{* *}$ & 1.000 \\
\hline & & Sig. (2-tailed) & .000 & \\
\hline & & $\mathrm{N}$ & 86 & 86 \\
\hline
\end{tabular}

**. Correlation is significant at the 0.05 level (2-tailed).

Since the rho-value is 0.572 , it means there is a positive correlation characterized with a strong relationship. Hence, the null hypothesis was rejected; which when interpreted means: informational justice is significantly related to identification with supervisor.

\subsection{Informational justice and internalization of supervisor's values (hypothesis two)}

H2: Informational justice is not significantly related to internalization of supervisor's values

Since the rho is 0.511 , its means there is a strong positive correlation. The null hypothesis was rejected; which when interpreted means: informational justice is significantly related to internalization of supervisor's values. 
Ajogwu Akoh, Edwinah Amah

Interactional Justice and Employees' Commitment to Supervisor in Nigerian Health Sector

Table 2: Test of hypothesis two: Correlations

\begin{tabular}{|rll|r|r|}
\hline & & Informational & Internalization \\
\hline Spearman's rho & Informational & Correlation & 1.000 & $.511^{* *}$ \\
& & Coefficient & & \\
& Sig. (2-tailed) & 86 & .000 \\
& $\mathrm{~N}$ & $.511^{* *}$ & 86 \\
\cline { 2 - 5 } & Internalization & Correlation & .000 & 1.000 \\
& Coefficient & 86 & .86 \\
& Sig. (2-tailed) & & \\
& $\mathrm{N}$ & & \\
& & &
\end{tabular}

**. Correlation is significant at the 0.05 level (2-tailed).

\subsection{Interpersonal justice and identification with supervisor (hypothesis three)}

H3: Interpersonal justice is not significantly related to identification with supervisor

Table 3: Test of hypothesis three: Correlations

\begin{tabular}{|lll|r|r|}
\hline & & Interpersonal & \multicolumn{1}{|c|}{ Identification } \\
\hline Spearman's rho & Interpersonal & Correlation & 1.000 & $.863^{\text {** }}$ \\
& & Coefficient & .00 & .000 \\
& Sig. (2-tailed) & 86 & 86 \\
& $\mathrm{~N}$ & $.863^{\star *}$ & 1.000 \\
\cline { 2 - 5 } & Internalization & Correlation & .000 & \\
& Coefficient & 86 & 86 \\
& Sig. (2-tailed) & & \\
& $\mathrm{N}$ & & \\
& & &
\end{tabular}

**. Correlation is significant at the 0.05 level (2-tailed).

Given that rho is $\mathbf{0 . 8 6 3}$, it means there is a strong positive correlation. Hence, the rejection of the null hypothesis; which when interpreted means: interpersonal justice is significantly related to identification with supervisor.

\subsection{Interpersonal justice and internalization of supervisor's values (hypothesis four)}

H4: Interpersonal justice is not significantly related to internalization of supervisor's values

Table 4: Test of hypothesis four: Correlations

\begin{tabular}{|c|c|c|c|c|}
\hline & & & Interpersonal & Internalization \\
\hline \multirow[t]{6}{*}{ Spearman's rho } & \multirow[t]{3}{*}{ Interpersonal } & $\begin{array}{l}\text { Correlation } \\
\text { Coefficient }\end{array}$ & 1.000 & $.749^{\star \star}$ \\
\hline & & Sig. (2-tailed) & & .000 \\
\hline & & $\mathrm{N}$ & 86 & 86 \\
\hline & \multirow[t]{3}{*}{ Internalization } & $\begin{array}{l}\text { Correlation } \\
\text { Coefficient }\end{array}$ & $.749^{* *}$ & 1.000 \\
\hline & & Sig. (2-tailed) & .000 & \\
\hline & & $\mathrm{N}$ & 86 & 86 \\
\hline
\end{tabular}

$* *$. Correlation is significant at the 0.05 level (2-tailed). 


\author{
Ajogwu Akoh, Edwinah Amah \\ Interactional Justice and Employees' Commitment to Supervisor in Nigerian Health Sector
}

Since the correlation coefficient is 0.749 , it follows that there is a strong positive relationship. Hence, the rejection of the null hypothesis; which when interpreted means: interpersonal justice is significantly related to internalization of supervisor's values.

\title{
5. DISCUSSION OF FINDINGS
}

H1: Informational justice is not significantly related to identification with supervisor

The spearman's rank correlation coefficient was used to analyze the relationship between informational justice and identification with supervisor. The analysis produced a result 0.572 rho value, with the significance level of 0.05 (two-tailed). This shows an average positive correlation between the variables. Hence, the employees of the selected hospitals had a close association with the supervisor and were satisfied to be subordinates to their supervisors, when informational justice was received from the supervisors. The result will not be the same if informational injustice is found. Instead of identifying with the supervisor, employees will be detached and psychologically divorced from their supervisors.

\section{H2: Informational justice is not significantly related to internalization of supervisor's values}

Data analysis resulted in the correlation value of 0.511 , using a level of significance of 0.05 (twotailed). This shows a reduced strength of the positive correlation between informational justice and internalization of supervisor's value, as opposed to the first hypothesis. However, both the first and second hypotheses returned average correlation values. The positive correlation indicates that employees/supervisor values congruence will be enhanced by adequate communication about work processes and outcomes from the supervisor.

\section{H3: Interpersonal justice is not significantly related to identification with supervisor}

The spearman's rank correlation coefficient was used to analyze the relationship between interpersonal justice and identification with supervisor. The analysis produced a result 0.863 correlation coefficient (rho), with the significance level of 0.05 (two-tailed). This shows a strong positive correlation between the variables. Hence, the employees had a close association with the supervisor and were satisfied to be subordinates to their supervisors, when they receive interpersonal justice from their supervisors. Hence, if the organization intends to increase the benefit of employees' commitment to supervisor, the organizational managers should improve interpersonal justice.

\section{H4: Interpersonal justice is not significantly related to internalization of supervisor's values}

Data analysis resulted in the correlation value of 0.749 , using a level of significance of 0.05 (twotailed). This shows a strong and positive correlation between interpersonal justice and internalization of supervisor's value. The significant positive correlation indicates that employees' values will be in congruence with their supervisors' values when they receive interpersonal justice. Hence, it can be concluded that there is significant relationship between interpersonal justice and internalization of supervisor's values.

Looking at the four hypotheses and the various correlation coefficients returned, it is noteworthy that whereas informational justice only returned average positive correlation with employees' commitment to supervisor, interpersonal justice returned strong positive correlations. Accordingly, it shows that informational justice is less impactful than an interpersonal relationship, in predicting the level of employees' commitment to supervisor.

\section{CONCLUSION}

The quality of interpersonal relationship and the nature of information available for employees depend on interactional justice. Employees attach themselves to supervisors that are fair in communication and relationship. The fairness of interactions and communications boost employees' confidence, impacting positively on employees' commitment to supervisor and making employees see themselves as part owners in the organization. Organizations that allow interactional injustices cannot go unpunished, as employees will definitely give back to the organization according to the 


\section{Ajogwu Akoh, Edwinah Amah \\ Interactional Justice and Employees' Commitment to Supervisor in Nigerian Health Sector}

measures they have received. Interactional injustice distorts organizational procedures and makes employees withdraw their efforts and themselves from the organization. This will certainly kill the drive and innovative spirit of employees.

Given that interpersonal justice is stronger than informational justice in predicting the level of employees' commitment to supervisor; we concluded that organizations stand to benefits more when they implement policies and programmes that increase interpersonal relationship in the workplace. Employees are more attached to supervisors that are fair in an interpersonal relationship than in communication. Overall, the fairness of interaction and communication boost employees' confidence, impacting positively on employees' commitment to supervisor and making employees see themselves as part owners in the organization. By implication, organizations must pursue interpersonal justice and informational justice in order to ensure that employees gain the needed confidence to innovate and sustain the spirit of a motivated workforce.

\section{RECOMMENDATIONS}

We recommend that organizational managers or supervisors should communicate and relate properly with employees, in order to satisfy their customers and other stakeholders. This study's findings set the ball rolling for related future studies. Some of these possible areas for future researches are mentioned hereunder.

First, it is recommended that moderating variables be introduced in future studies in order to determine the effect of other variables such as: employee age, tenure of employee with supervisor and unemployment effect (e.g., fear of dismissal). The earlier work of Akoh and Amah, (2015) suggests that commitment to supervisor could take the pseudo form; hence this possibility could be properly tested and determined by introducing other relevant moderating variables.

Second, studies in the future can also be done using the longitudinal research design, so as to study the spread of employment conditions. This will help to avoid the single point measurement approach undertaken by this study.

Third, this work studied employees of private organizations and may have more frequent supervisor interactions, leading to closer identification with supervisors. HR management systems in the public institutions may differ; hence, closer relationship with supervisor may have little or no attention. Hence, studies in the future should examine the relevance of these findings to public institutions.

Again, the study of justice in the Nigerian environment should be taking to HR practices such as: planning, recruitment, selection, retention and so forth. Lastly, similar studies might be carried out to further research both the dependent and independent variables of this study in other sectors of the economy and even different geographical locations.

\section{References}

- Akoh, A. and Amah, E. (2015). Distributive Justice and Employees' Commitment to Supervisor in selected Hospitals in Rivers State, Nigeria. The Journal of Business and Management, 3(12), 122-128

- Bateman, T. S., and Organ, D. W. (1983). Job satisfaction and the good soldier: The relationship between affect and employee citizenship. Academy of Management Journal, 26(4), 587-595, CrossRef

- Becker, T. E., Billings, D. M., Eveleth, D. M., and Gilbert, N. L. (1996). Foci and bases of employee commitment: Implications for job performance. Academy of Management Journal, 39, 464-482, CrossRef

- Bies, R. J., and Shapiro, D. L. (1987). Interactional justice: The influence of causal accounts. Social Justice Research, 1, 199-218, CrossRef 
- Chen Z. X., Tsui A. S., and Farh J. (2002). Loyalty to supervisor vs. organizational commitment: Relationships to employee performance in China. Journal of Occupational and Organizational Psychology, 75(3), 339-356, CrossRef

- Cohen-Charash, Y., and Spector, P. E. (2001). The role of justice in organizations: A metaanalysis. Organizational Behavior and Human Decision Processes, 86, 278-321, CrossRef

- Colquitt, J. A., Conlon, D. E., Wesson, M. J., Porter, C. O. L. H., and Ng K.Y. (2001). Justice at the millennium: A meta-analytic review of 25 years of organizational justice research. Journal of Applied Psychology, 86(3), 425-445, CrossRef

- Colquitt, J. A. (2001). On the dimensionality of organizational justice: A construct validation of a measure. Journal of Applied Psychology, 86, 386-400, CrossRef

- Cropanzano, R. Prehar, C. A. and Chen P. Y. (2002). Using social exchange theory to distinguish procedural from interactional justice. Group and Organization Management, 27(3), 324-351, CrossRef

- Ebener, D. R., and O'Connell, D. J. (2010). How might servant leadership work? Nonprofit Management and Leadership, 20(3), 315-335, CrossRef

- Folger, R., and Cropanzano, R. (1998). Organizational justice and human resources management. Thousand Oaks, London: Sage.

- Gregersen, H. B. (1993). Multiple commitments at work and extra-role behavior during three stages of organizational tenure. Journal of Business Research, 26, 31-47, CrossRef

- Kelman, H. C. (1958). Compliance, identification, and internalization: Three processes of attitude change. Journal of Conflict Resolution, 2, 51-60, CrossRef

- Lind, E. A., and Tyler, T. R. (1988). The social psychology of procedural justice. New York: Plenum, CrossRef

- Masterson, S. S., Lewis, K., Goldman B. M. and Taylor, M. S. (2000). Integrating justice and social exchange: The differing effects of fair procedures and treatment of work relationships. Academy of Management Journal, 43, 738-748, CrossRef

- McCardle J. G. (2007). Organizational justice and workplace deviance: The role of organizational structure, powerlessness, and information salience (Unpublished doctoral dissertation). University of Central Florida, Orlando, Florida

- McManus, K. (2002). Management by nagging (a lot). "Institute of industrial engineers solutions, 34, 19

- Mikula, G., Petri, B., and Tanzer, N. K. (1990). What people regard as unjust: Types and structures of everyday experiences of injustice. European Journal of Social Psychology, 20, 133-149, CrossRef

- Nwibere, B. M. and Olu-Daniels, S. O. (2014). Trust and Employees' Commitment to Supervisor: The Nigerian experience. European Journal of Business and Management, 6(8), $121-133$

- O'Reilly, C. A. and Chatman, J. (1986). Organizational commitment and psychological attachment: The effects of compliance, identification, and internalization on pro-social behavior. Journal of Applied Psychology, 71, 492-499, CrossRef

- Sheppard, B. H., Lewicki, R. J., and Minton, J. W. (1992). Organizational justice: The search for fairness in the workplace. Newyork: Maxwell Macmillan International.

- Sokoll, S. (2014). Servant leadership and employee commitment to a supervisor. International Journal of Leadership Studies, 8(2), 89 - 104.

- Tsai, M. C., (2012). An empirical study of the conceptualization of overall organizational justice and its relationship with psychological empowerment, organizational commitment and turnover intentions in higher education (Unpublished doctoral dissertation). University of Washington.

- Turnley, W. H., and Feldman, D. C. (1999). The impact of psychological contract violations on exit, voice, loyalty, and neglect. Human Relations, 52, 895-922, CrossRef, CrossRef 